\title{
Frequency distribution of polymorphic variants of the beta-casein locus in Russian various breed cattle subpopulations
}

\author{
Natalia Kovalyuk ${ }^{1, *}$, Elena Shiryaeva ${ }^{1}$, Lyudmila Yakusheva $^{1}$, Vladimir Kaishev ${ }^{2}$, and \\ Zaurbek Aisanov ${ }^{3}$ \\ ${ }^{1}$ Federal State Funded Research Institution "Krasnodar Research Center for Animal Husbandry and \\ Veterinary Medicine", Pervomayskaya Str., 4, 350055 Krasnodar, Russia \\ ${ }^{2}$ Federal State Budgetary Educational Institution of Higher Education Southern Federal University, \\ Sadovaya Str., 105/42 B., 344006 Rostov-on-Don, Russia \\ ${ }^{3}$ Kabardino-Balkarian State Agricultural University named after V. M. Kokov, Lenin Avenue, 1V, \\ 360030 Nalchik, Russia
}

\begin{abstract}
Using the author's test system, 2607 Holstein, Ayrshire and Jersey breeds were genotyped at CSN2 locus. It was determined that the frequency of preferred genotype A2A2 is in Holstein, Ayrshire and Jersey groups of animals $-0.21 ; 0.25$ and 0.60 respectively. The frequency of $\mathrm{A} 2$ allele in Holstein breed is 0.48; in Ayrshire - 0.51; in Jersey - 0.78. Thus, the Russian subpopulations of Ayrshire, Jersey, and Holstein cattle subpopulations according to frequencies of A2A2 genotypes (CSN2 locus), the Jersey breed has the best indicators (0.60). Russian breeding enterprises selling semen production of Ayrshire and Holstein bulls should increase the share of breeders with CSN2 genotypes A2A2.
\end{abstract}

\section{Introduction}

For $\beta$-casein gene (CSN2), 12 polymorphic variants were described. The A1 and A2 alleles are known to be the most frequent genetic variants of the CSN2 casein protein $[1,2]$. It was concluded that the mutation causing differences in the casein protein is considered the result of a single nucleotide polymorphism (C/A) in codon 67 in exon 7 of the beta-casein gene, that is the CCT codon (A2, proline) is changed to CAT (A1, histidine)). Many researchers [3,4], [4-7] believe that the bioactive peptide $\beta$-casomorphin 7 , derived from casein A1 variants, can cause coronary heart disease in humans, atherosclerosis, type I diabetes mellitus, sudden infant death and autism syndromes.

It is believed that this mutation arose about 5000 years ago and spread widely in various cattle breeds. It was detected [4] that in such dairy cattle breeds as Guernsey, Schwyz, Jersey, Holstein, Ayrshire and Red Danish the frequency of the A1 allele ranges within 4$2 \%, 34-30 \%, 50-37 \%, 56-47 \%, 60-51 \%$ and $77 \%$, respectively.

\footnotetext{
*Corresponding author: skniig@yandex.ru
} 
In light of the ever-increasing requirements for dairy products quality, it is important to determine the potential of Russian subpopulations of Holstein, Ayrshire and Jersey breeds in terms of beta-casein locus selection.

\section{Materials and Methods}

Studies on the frequency of genotypes and alleles, tested at the beta-casein locus of cows were based on Federal State Funded Research Institution "Krasnodar Research Center for Animal Husbandry and Veterinary Medicine" and NPO Yug-Plem LLC in the laboratories of biotechnology and molecular genetic expertise. 2607 animals of the following cattle breeds were analyzed: Holstein $(n=1081)$ (Agroobedinenie Kuban JSC), Ayrshire $n=917$ (Ilchenko Yu.V. Peasant Farm, A.I. Ezubov Peasant Farm) and Jersey $n=609$ (Agroalliance Invest LLC).

United States Patent 7094949 (McLachlan CN (2006) Breeding and milking cows for milk free of $\beta$-casein A1) describes a technology for animal genotyping at beta-casein locus (CSN2) to identify cows, carrying the A2 genotype. Studies by M. Miluchova, M. Gabor, A. Trakovicka (2013) and others [8] used the PCR/RFLP technology described in the patent. The studies detected an unsuccessful structure of one of the primers, characterized by a length of 33 base pairs and forming hairpins with quite a high probability, which is the main feature of this test system. Therefore, we have proposed our own genotyping system.

Diatom $^{\text {TM }}$ DNA Prep 100 systems (Isogen Laboratory LLC, Moscow) were used for DNA isolation from blood. To set up a PCR reaction, we used Gene Pak PCR Core systems (Laboratory Izogen, Moscow), primer selection was performed using the Primer Premier program, and amplification was performed empirically.

To create a restriction site in the required SNP $(T \rightarrow G)$ area, it was necessary to introduce a nucleotide substitution into one of the primers. The following primers were used:

\section{5'AGG GAT GTT TTG TGG GAG GCT CTT3'}

5'ATA AAA TCC ACC CCT TTG CCC AGA 3'

As a result, the fragments, amplified from the region of the $\beta$-casein variant A2 gene, were cleaved by BstDEI endonuclease (No. E227, NPO SibEnzyme) into 2 fragments: 64 and $22 \mathrm{bp}$. The fragment amplified from the A1 allele had no restriction site (its size was 86 bp). Restriction results were evaluated on a $2.5 \%$ agarose gel (Fig. 1).

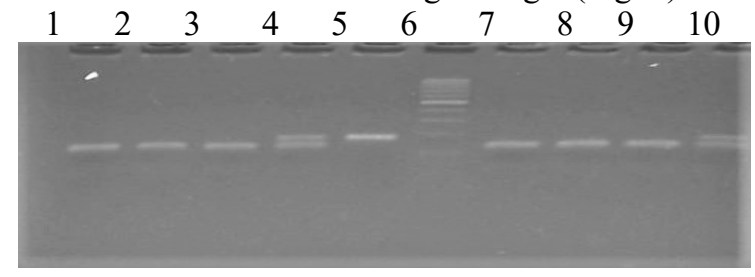

Fig. 1. Electropherogram of hydrolysis products of the CSN2 gene region amplificates by the BstDEI endonuclease restriction 1,2,3,7,8,9 - A2A2 genotype; 4, 10 - A1A2 genotype; 5 - A1 A1 genotype; 6 molecular weight marker;

\section{Results and Discussion}

The actual frequency of individual genotypes was determined by the ratio of the number of carriers of a particular genotype to the total number of individuals in the analyzed group. In this case, the allele frequencies were calculated using the following formula: $P(A)=(2 N 1$ $+\mathrm{N} 2) / 2 \mathrm{n}$, where $\mathrm{N} 1$ is the number of homozygotes at the considered allele, N2 is the number of heterozygotes, $\mathrm{n}$ is the sample size. 
The frequency distribution of genotypes and alleles, tested at the beta-casein locus of various breed cows is shown in Table 1 .

Table 1. Frequency distribution of genotypes and alleles in dairy breed cows.

\begin{tabular}{|c|c|c|c|}
\hline \multirow{3}{*}{ Genotype/allele } & \multicolumn{3}{|c|}{ Frequency of CSN2 genotypes and alleles } \\
& \multicolumn{3}{|c|}{ in } \\
\cline { 2 - 4 } & $\begin{array}{c}\text { Holstein breed, }(\mathrm{n}= \\
1081)\end{array}$ & $\begin{array}{c}\text { Ayrshire breed, }(\mathrm{n}= \\
917)\end{array}$ & $\begin{array}{c}\text { Jersey breed, }(\mathrm{n}= \\
609)\end{array}$ \\
\hline $\mathrm{A} 1 \mathrm{~A} 1$ & 0.26 & 0.24 & 0.04 \\
\hline $\mathrm{A} 1 \mathrm{~A} 2$ & 0.53 & 0.51 & 0.36 \\
\hline $\mathrm{A} 2 \mathrm{~A} 2$ & 0.21 & 0.25 & 0.60 \\
\hline A1 & 0.52 & 0.49 & 0.22 \\
\hline A2 & 0.48 & 0.51 & 0.78 \\
\hline
\end{tabular}

It was determined that the frequency of preferred genotype A2A2 is in Holstein, Ayrshire and Jersey groups of animals $-0.21 ; 0.25$ and 0.60 respectively. The frequency of A2 allele in Holstein breed is 0.48; in Ayrshire - 0.51; in Jersey - 0.78. The obtained results are, in general, consistent with those obtained by other researchers.

\section{Conclusions}

Thus, the Russian subpopulations of Ayrshire, Jersey, and Holstein cattle subpopulations according to frequencies of A2A2 genotypes (CSN2 locus), the Jersey breed has the best indicators (0.60). We consider it expedient for domestic breeding enterprises selling semen production of Ayrshire and Holstein bulls to increase the share of breeders with CSN2 genotypes A2A2 (CSN2 locus).

\section{References}

1. H. M. Farrell, R. Jimenez-Flores, G. T. Bleck, E. M. Brown, J. E. Butler, L. K Creamer, H. E. Swaisgood, Nomenclature of the proteins of cows' milk (2004)

2. S. Kaminski, A. Cieslinska, E. Kostyra, Polymorphism of bovine -casein and its potential effect on human health, 48, 189-198 (2007)

3. A. Cieslinska, E. Kostyra, H. Kostyra, K. Olenski, E. Fiedorowicz, S. Kaminski, Int. J. Food Sci. Nutr., 63, 426-430 (2012)

4. A. Parashar, R. K Saini, Int. J. of Bioassays, 4(12), 4611-4619 (2015)

5. A. Cieslinska, E. Sienkiewicz-Szłapka, J. Wasilewska, E. Fiedorowicz, B. Chwała, M. Moszynska-Dumara, E. Kostyra, Influence of candidate polymorphisms on the dipeptidyl peptidase IV and opioid receptor genes expression in aspect of the $\beta$ casomorphin-7 modulation functions in autism Peptides, 65, 6-11 (2015)

6. V. Petrat-Melin, P. Andersen, J. T. Rasmussen, N. A. Poulsen, L. V. Larsen, J. F. Young, J. Dairy Sci., 98, 15-26 (2015)

7. K L. Reichelt, Bioengineer D. Tveiten, A. M. Knivsberg, G. Brønstad, Microb. Ecol. Health D, 23, 18958 (2012)

8. M. Miluchova, M. Gabor, A. Trakovicka, ABP, 60(4), 799-801 (2013) 